\title{
The study of the calculation of energy consumption load for heating and cooling in building using the Laplace Transform solution
}

\author{
Kyu-Il HAN* \\ Department of Mechanical System Engineering, Pukyong National University, Busan 608-739, Korea
}

\begin{abstract}
The Laplace Transform solution is used as a mathematical model to analyse the thermal performance of the building constructed using different wall materials. The solution obtained from Laplace Transform is an analytical solution of an one dimensional, linear, partial differential equation for wall temperature profiles and room air temperatures. The main purpose of the study is showing the detail of obtaining solution process of the Laplace Transform. This study is conducted using weather data from two different locations in Korea: Seoul, Busan for both winter and summer conditions. A comparison is made for the cases of an onoff controller and a proportional controller. The weather data are processed to yield hourly average monthly values. Energy consumption load is well calculated from the solution. The result shows that there is an effect of mass on the thermal performance of heavily constructed house in mild weather conditions such as Busan. Building using proportional control experience a higher comfort level in a comparison of building using on-off control.
\end{abstract}

Keywords : Laplace Transform, steady state, energy consumption load, thermal performance, comfort level

\section{Introduction}

Reducing energy consumption load in residential and industrial buildings has been focused for a long time due to rapidly rising costs of heating in winter and cooling in summer time, About more than $10 \%$ of the total energy in Korea is required for residential space heating and cooling. Some works (Peavy et al., 1973, Kusuda, 1976) have been done and many methods have been developed to obtain energy consumption loads for residential buildings. This concept is first introduced using what they call room thermal response factors (Stephenson and Mitalas, 1967, Mitalas and Stephenson, 1967). Their method for procedure is that the internal wall surface temperatures of residential buildings and cooling or heating load are first calculated in a rigorous manner for several typical constructions. A computer model for simulating heat flow by conduction through walls and roofs is developed based on the transmission matrix method (Buff- ington, 1975). The transmission matrix method relates the periodic temperature and heat flux on one side of a homogeneous layer to the periodic temperature and heat flux on the other side by means of a transmission matrix. The main advantage of the transmission matrix method is the simplicity with which the model describes transient inside air temperatures.

Gadgil et al. (1982) find that variation in convection coefficients can have substantial effects on thermal loads for a structure. Computer programs are developed to simulate numerically natural convection in two and three dimensional room geometries. Christensen and Perkins (1981) describe the effects of typical internal gain assumptions in energy calculations. The results of this study indicate that calculations of annual heating and cooling loads are sensitive to the average internal gains, but, in most cases, are relatively insensitive to hourly variations in internal gains.

*Corresponding author: kihan@pknu.ac.kr, Tel: 82-51-629-6194, Fax: 82-51-629-6188 
Sodha et al. (1986) predict energy loads using an Admittance method and a Fourier method. The Admittance method is used to solve the problem using matrix equations, relating the temperature and energy cycle. the aim of the study is to compare the results obtained by two methods for the same system under identical conditions. It is shown that the two methods match well. The maximum deviation in the auxiliary energy rate at any hour is about 100 of the amplitude.

Although there are sophisticated energy calculation procedures available (Incropera et al., 2013) based upon the detailed dynamic simulation of hourly and sometimes minute-by-minute building performance inclusive of shell heat transfer, utility system, and equipment, the application of these detailed procedures requires large-scale computer systems, extensive labor to prepare input decks, and significant computer usage costs. Large computer programs are generally impractical for most applications. In other words, refined and sophisticated calculation procedures are unfortunately both time-consuming and expensive.

The main purpose of this study is showing how to obtain the Laplace transformation solution in detail as a mathematical model. And the thermal performance of the building constructed with different wall materials can be analysed using Laplace transform solution.

\section{Theoretical formulation for analytical solution}

The formulation of an analytical method for obtaining wall temperature profile, room air temperature, and energy consumption load is presented. Two houses with different wall materials in different weather conditions are modelled. Each test house is a $6.1 \mathrm{~m}$ by $6.1 \mathrm{~m}$ by $2.3 \mathrm{~m}$ one-room house. The houses have identical floor plans and orientations, and are identical except for wall construction, which is as follows: insulated lightweight wood frame; insulated masonry with outside mass. The details of the wall construction for each of the two houses are presented in Table 1.

Weather data for two cities (Seoul, Busan) are used in this study. Twenty-four discrete data points from weather data files are converted to continuous form via a Fast Fourier Transform (Brigham, 1974). Each house is modelled by a single homogeneous wall and an air node.

The thermal system is illustrated in Fig. 1. It is represented mathematically by two energy balances: one on the wall, and the other on the room air. The case studied represents a linear flow of heat in a solid wall bounded by a pair of parallel planes, at $\mathrm{x}=0$ and $\mathrm{x}=\mathrm{L}$ (Kreyszig, 2011). The system is considered as one-dimensional. the heat flow occurs principally in the direction perpendicular to the thickness of the

Table 1. Wall construction types

\begin{tabular}{l}
\hline House \#1 : insulated lightweight wood frame \\
\hline $13 \mathrm{~mm}$ gypsum board \\
$0.05 \mathrm{~mm}$ polyethylene film \\
R-11 $16 \mathrm{~mm}$ exterior plywood \\
House \#2: insulated masonry (outside mass) \\
\hline $13 \mathrm{~mm}$ gypsum board \\
$0.05 \mathrm{~mm}$ polyethylene film \\
$51 \mathrm{~mm}$ thick extruded polystyrene insulation \\
$6.4 \mathrm{~mm}$ air space \\
$100 \mathrm{~mm}$ 2-core hollow concrete block $\left(1680 \mathrm{~kg} / \mathrm{m}^{3}\right)$ \\
$100 \mathrm{~mm}$ face brick
\end{tabular}

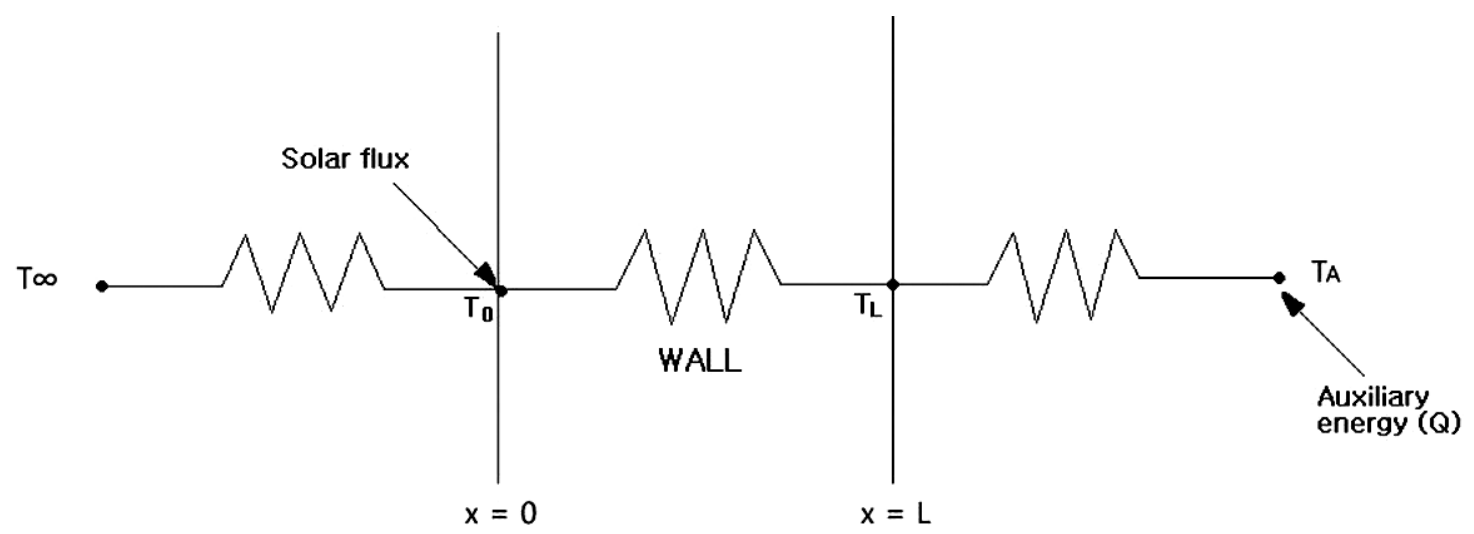

Fig. 1. Thermal system. 
wall (x-direction).

Under this study there is no heat generation within the wall, and the energy balance, after some manipulation, yields:

$$
\partial^{2} T / \partial x^{2}=(1 / \alpha) \partial T / \partial t
$$

Two corresponding boundary conditions to the above linear, second-order, partial differential equation are:

$$
\begin{aligned}
& -k \partial T / \partial x(x=0)=\hat{a} S^{*}+h_{e}\left(T_{\infty}-T_{0}\right) \\
& -k \partial T / \partial x(x=L)=-h_{i}\left(T_{A}-T_{L}\right)
\end{aligned}
$$

The initial condition for the wall temperature is expressed in polynomial form as:

$$
T(x, 0)=\sum_{n=0}^{4} a_{n} x^{n}
$$

The energy balance (Oosthuizen and Naylor, 1999) for the room air temperature including heat transfer from the inside surface of the wall, infiltration loss I, and auxiliary heat input Q, is:

$$
\begin{aligned}
& C_{A} d T_{A} / d t=-h_{i} A\left(T_{A}-T_{L}\right)-C_{A}{ }^{\prime} \boldsymbol{I}\left(T_{A}-T_{\infty}\right)+Q \\
& C_{A}=\left(\rho C_{v}\right)_{A} V_{A} \\
& C_{A}{ }^{\prime}=\left(\rho C_{p}\right)_{A} V_{A} \\
& \boldsymbol{I}^{\prime}=C_{A}{ }^{\prime} \boldsymbol{I} / C_{A}
\end{aligned}
$$

The parameters, $h_{i}, h_{e}, C_{A}, C_{A}{ }^{\prime}$ and I are assumed constant. The corresponding initial condition to equation (5) is as follows:

$$
T_{A}(0)=T_{i}
$$

There exists a coupling between wall and room air temperatures (Modelst, 1993), and the two sets of equations must be solved simultaneously. Weather data for two cities are used in this study. weather data files are used to obtain hourly values of the solar flux and ambient temperature. The weather data input to the analytical model is finally represented in the following form:

$$
\begin{gathered}
S^{*}(t)=b_{0}+\sum_{i=1}^{11}\left[b_{i} \cos \left(w_{i} t+\Phi_{i}\right)+c_{i} \sin \left(w_{i} t+\Phi_{i}\right)\right] \\
T_{\infty}(t)=d_{0}+\sum_{i=1}^{11}\left[d_{i} \cos \left(w_{i} t+\Phi_{i}\right)+e_{i} \sin \left(w_{i} t+\Phi_{i}\right)\right]
\end{gathered}
$$

where $b_{0}$ is the DC component of the solar flux and $d_{0}$ is the DC component of the ambient temperature. Such analytical functions can be easily integrated and differentiated so as to facilitate the solution process. The calculation method to obtain effective properties for buildings and thermal transport parameters such as heat transfer coefficients are introduced.

The effective properties based on Marks' standard handbook (1978) of a homogeneous wall, which represents the actual building ls wall, are necessary to obtain an analytical solution. Use of such properties is inevitable to simplify the analytical solution. The effective properties are shown in Table 2

Effective thermal properties such as thermal conductivity, thermal diffusivity, thermal capacitance, and thermal resistance, which represent the wall as a single homogeneous unit can be computed based on matching: (1) the wall length (summation of the Length of wall components), (2) the thermal resistance, (3) the thermal capacitance of the materials comprising the wall, and additionally, (4) the time delays for a thermal pulse to penetrate the wall.

It is desired to maintain comfort inside the building. In order to accomplish this practically, the rate of supply of heat to the building is regulated by a controller. Two types of control mechanisms are chosen for investigation. One is a simple 'on-off' controller; the other is a proportional controller.

The on-off controller is very popular both in residential and commercial buildings because of its simplicity of operation (Winn, 1982). The control logic is depicted in Fig. 2. The rate of supply of heat $(\mathrm{Q})$ from the auxiliary energy source switches on or off depending on the difference between the inside room air temperature and the set-point tem-

Table 2. Effective Properties

\begin{tabular}{ccccc}
\hline House & $\begin{array}{c}\mathrm{k} \\
\left(\mathrm{W} / \mathrm{m}^{\circ} \mathrm{C}\right)\end{array}$ & $\begin{array}{c}\mathrm{L} \\
(\mathrm{m})\end{array}$ & $\begin{array}{c}\alpha \\
\left(\mathrm{m}^{2} / \mathrm{s}\left(\times 10^{7}\right)\right)\end{array}$ & $\begin{array}{c}\rho^{*} C_{p} \\
\mathrm{~J} /{ }^{\circ} \mathrm{Cm}^{3}\end{array}$ \\
\hline$\# 1$ & 0.0549 & 0.118 & 2.0352 & 269752.5 \\
$\mathrm{~m}^{2 \circ} \mathrm{C} / \mathrm{W}$ & 0.9025 & 2.148 \\
\hline 2 & 0.1136 & 0.274 & 2.413 & 1258791.9 \\
\hline
\end{tabular}




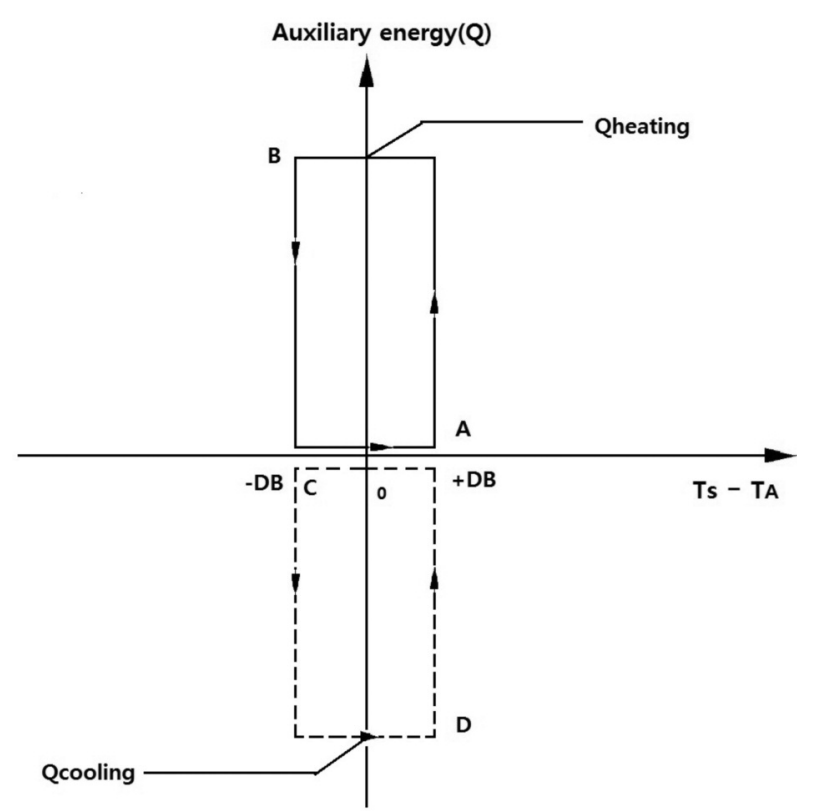

Fig. 2. On-off controller system.

perature. A set-point temperature of $22^{\circ} \mathrm{C}$ is used. Heating begins at point $\mathrm{A}$ (cooling for the corresponding point on the other side, C). This auxiliary energy will be deactivated as the temperature exceeds point $\mathrm{B}$ (or $\mathrm{D}$, respectively).

If a dead band was not used, it would lead to rapid cycling of the auxiliary energy source. The cycling rate can, however, be reduced by introducing a dead band. As explained above, the effect of the dead band is that the controller will not activate the energy source until the actual room air temperature drops below the lower bound of the dead band. Comfort level can be increased by using a small dead band although this results in a greater cycling rate, reducing heating plant efficiency. Choosing a suitable value of $\mathrm{Q}$ is also important.

The rate of supply of heat produced by the proportional controller is modelled as proportional to the difference between the set-point temperature and the room air temperature as:

$$
Q=\Gamma\left(T_{S}-T_{A}\right)
$$

Thus, if the room air temperature is very low, the heating source will work hard to overcome the temperature difference (i.e. $\left.T_{S}-T_{A}\right)$. However, as the actual room air temperature $\left(T_{A}\right)$ approaches the set-point temperature $\left(T_{S}\right)$, the

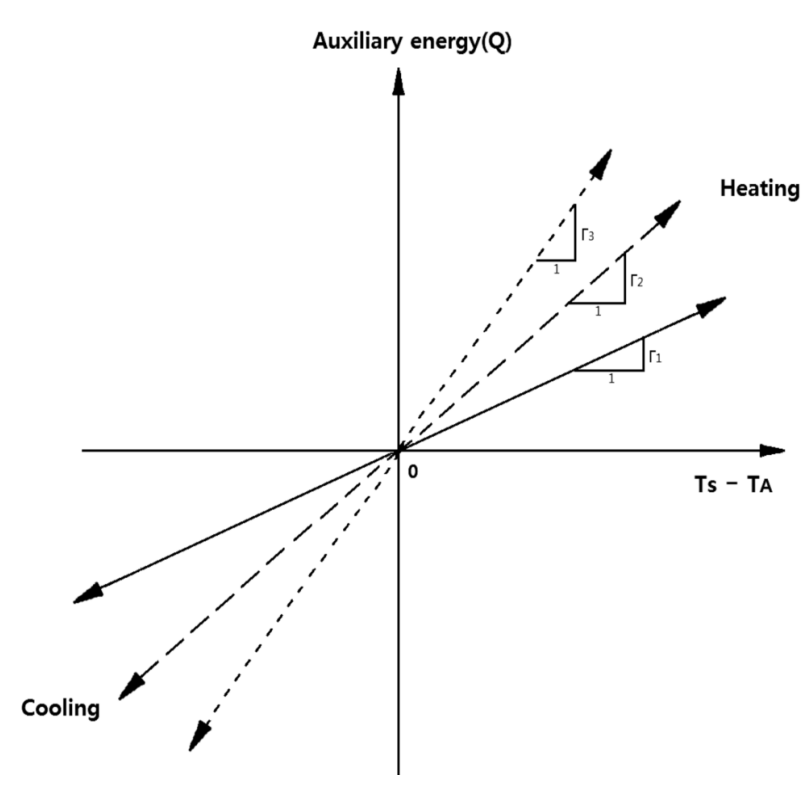

Fig. 3. Proportional controller system.

output of the energy source decreases, there by preventing overshoot (Winn, 1982).

Fig. 3 represents the logic of this controller. As shown in the Figure, the slope of the line, $\Gamma$, is referred to as the controller gain. The disadvantage of the proportional controller, as illustrated, is that it would cause the energy source to operate continuously. At low energy rates, this results in inefficiency of the heating plant. The heating region or the cooling region in the Figure is determined depending upon the positive or the negative sign of $\left(T_{S}-T_{A}\right)$. There is no dead band in the proportional controller in this study.

In many problems, the number of dimensional variables and parameters is large. Non-dimensionalization can be used to arrange these quantities into a smaller number of parameters. The physically significant parameters appear either in the differential equation or in boundary or initial conditions through a non-dimensionalization.

the solution can be represented in non-dimensional parameterized form as follows:

$$
\begin{aligned}
T= & T\left(x^{\prime}, t^{\prime}, F O, B i_{1}, B i_{2}, \hat{a} L S^{*} /(k \Delta T), \Delta T_{A} / \Delta T,\right) \\
& \left.Q L^{2} /\left(C_{A} \alpha \Delta T\right), \text { inital conditions }\right)
\end{aligned}
$$

where the two Biot numbers are:

$$
B i_{1}=h_{e} L / k
$$




$$
B i_{2}=h_{i} L / k
$$

\section{Laplace transform solution}

The Laplace transform approach was adopted, and proved to be successful although the inversion from the Laplace domain to the real time domain was extremely complicated due to higher order poles. The Laplace transform method lends itself particularly well to the solution of linear, time-dependent problems. A transformation of the time variable essentially removes time from the transformed problem, rendering it easier to solve than the original equation. The formulation of the no auxiliary energy case can be easily obtained by setting $\mathrm{Q}$ in equation (5) to zero. This yields the "free response" of the building.

Many excellent references exist on the Laplace transform technique. The reader is referred to Carslaw and Jaeger (1959) for its application to thermal problems. As the technique is well known, only an outline of the solution procedure will be given here. The development of the solution begins via transformation of equation (1) to the Laplace domain, s, as follows:

$$
d^{2} T(x, s) / d x^{2}-s T(x, s) / \alpha+\left(\sum_{n=0}^{4} a_{n} / x^{n}\right) / \alpha=0
$$

Boundary conditions, equations (2) and (3), transformed to the s-domain as follows:

$$
d T(x, s) / d x(x=0)=-\hat{a} S^{*}(s) / k-h_{e}\left(T_{\infty}(s)-T_{0}(s)\right) / k
$$

$$
d T(x, s) / d x(x=L)=h_{i}\left(T_{A}(s)-T_{L}(s)\right) / k
$$

As the right-hand side of equation (1) is first order in time, the initial condition is incorporated in equation (16) in the process of transformation. Equation (5) for the air temperature is transformed to:

$$
(s+\beta) T_{A}(s)-T_{i}=M T_{L}(s)+\boldsymbol{I}^{\prime} T_{\infty}(s)+Q /\left(C_{A} s\right)
$$

where:

$$
\begin{gathered}
M=h_{i} A / C_{A} \\
\beta=M+I^{\prime}
\end{gathered}
$$

The weather data, equations (10) and (11), are transformed to:

$$
\begin{aligned}
S^{*}(s)= & b_{0} / s+\sum_{i=1}^{11}\left[\left(b_{i}\left(s \cos \Phi_{i}-w_{i} \sin \Phi_{i}\right)\right.\right. \\
& \left.\left.+c_{i}\left(s \sin \Phi_{i}+w_{i} \cos \Phi_{i}\right)\right) / s^{2}+w_{i}^{2}\right] \\
T_{\infty}(s)= & d_{0} / s+\sum_{i=1}^{11}\left[\left(d_{i}\left(s \cos \Phi_{i}-w_{i} \sin \Phi_{i}\right)\right.\right. \\
& \left.\left.+e_{i}\left(s \sin \Phi_{i}+w_{i} \cos \Phi_{i}\right)\right) / s^{2}+w_{i}^{2}\right]
\end{aligned}
$$

Equations (16) through (23) require solution simultaneously to obtain expressions for the wall temperature profile and the room air temperature in the Laplace domain. The solution in the transformed domain for the wall temperature profile is:

$$
\begin{aligned}
T(x, s)= & A(s) \cosh (p x)+B(s) \sin h(p x)+k_{0}(s)+K_{1}(s) x \\
& +K_{2}(s) x^{2}+K_{3}(s) x^{3}+K_{4}(s) x^{4} \\
T_{A}(s)= & {\left[T_{i}+M T_{L}(s)+I^{\prime} T_{\infty}(s)+Q /\left(C_{A} s\right)\right] /(s+\beta) }
\end{aligned}
$$

The inversion can be obtained using a Bromwich contour theory based on Carslaw and Jaeger (1959). The form of the wall temperature as a function of time is:

$$
\begin{aligned}
T(x, t) & =\sum_{m=1}^{\infty}\left[\left(A_{m} / C_{m}\right) \operatorname{EXP}\left(-\alpha \eta_{m}^{2} t\right) \cos \left(\eta_{m} x\right)\right. \\
& \left.+\left(B_{m} / C_{m}\right) \operatorname{EXP}\left(-\alpha \eta_{m}^{2} t\right) \sin \left(\eta_{m} x\right)\right) \\
& +\sum_{i=1}^{11}\left[x_{1 i}(x) \cos \left(w_{i} t\right)+x_{2 i}(x) \sin \left(w_{i} t\right)\right]+f(x, t)
\end{aligned}
$$

The form of the room air temperature as a function of time is:

$$
\begin{aligned}
T_{A}(t)= & \sum_{m=1}^{\infty}\left[\left(A_{m} / D_{m}\right) M \cos \left(\eta_{m} L\right) \operatorname{EXP}\left(-\alpha \eta_{m}^{2} t\right)\right. \\
& +\left(B_{m} / D_{m}\right) M \sin \left(\eta_{m} L\right) \operatorname{EXP}\left(-\alpha \eta_{m}^{2} t\right) \\
& +\sum_{i=1}^{11}\left[k_{1} \cos \left(w_{i} t\right)+k_{2} \sin \left(w_{i} t\right)\right]+f_{2}(x)+K_{3}
\end{aligned}
$$

where $\eta_{m}$ is the $m^{\text {th }}$ root of the characteristic equation, and Fig. 4 are showing these roots.

$$
\tan \left(L \eta_{m}\right)=\left[-\eta_{m} K_{4}\right] / K_{5}
$$

The only the difference between the proportional controller and the on-off controller is in the form of Q, In this instance equation (5) becomes:

$$
C_{A} d T_{A} / d t=-h_{i} A\left(T_{A}-T_{L}\right)-C_{A}{ }^{\prime} \boldsymbol{I}\left(T_{A}-T_{\infty}\right)+\Gamma\left(T_{S}-T_{A}\right)
$$




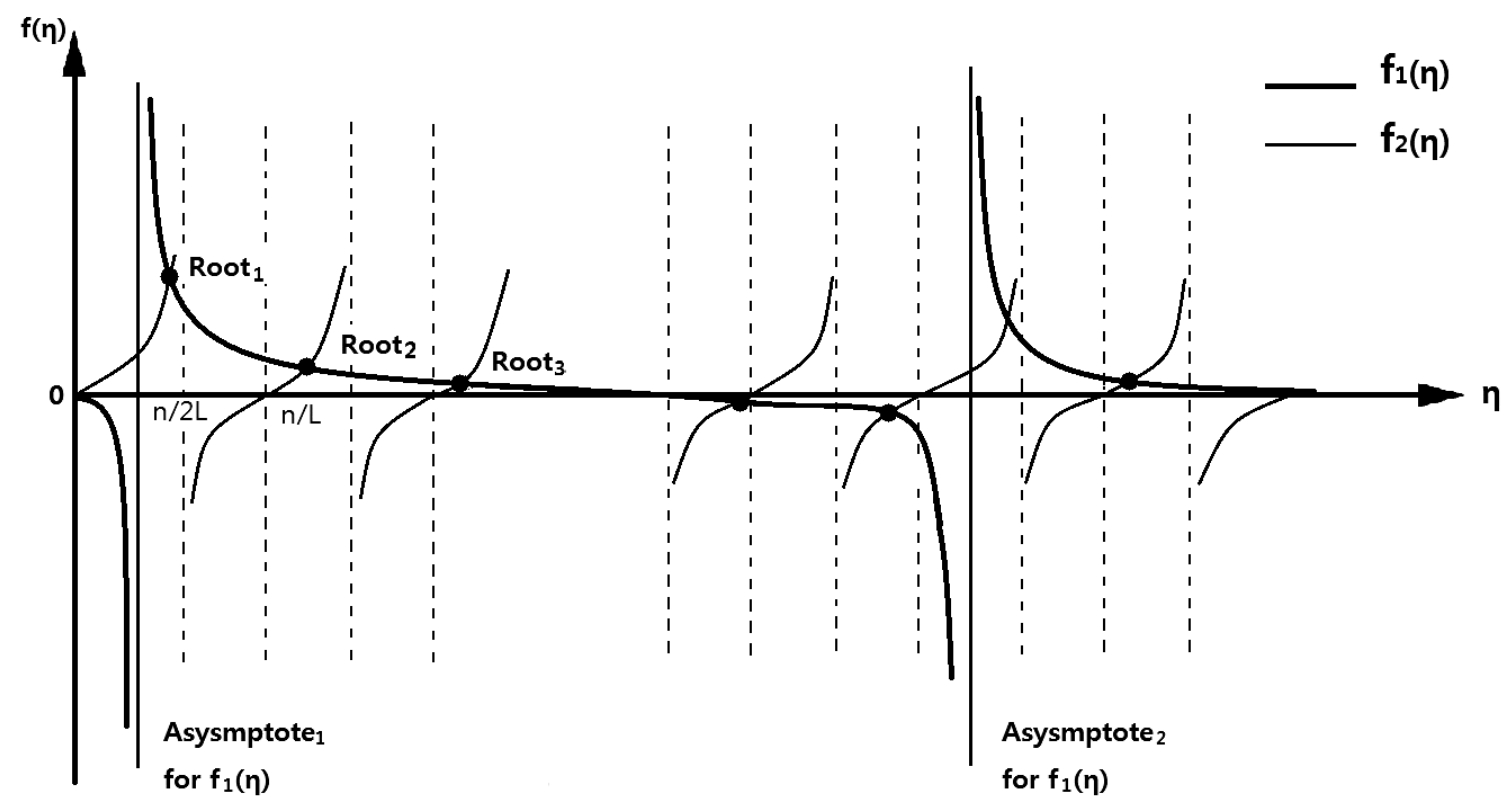

Fig. 4. Roots of the characteristic equation.

The governing equation, boundary conditions, and condition are the same as for the on-off controller. Although only the auxiliary energy term is replaced, the solution for this case differs from the solution for the on-off controller.

\section{Results and discussion}

The solution procedure is selected to yield a daily simulation which is independent of the (arbitrarily selected) initial condition. This is done by simulating over a sufficient number of identical days until the net daily internal energy stored in the wall is less than $0.25 \%$. Generally, 7 or 8 iterations (days of simulation) are required to converge, depending on the house and the weather data. Energy loads are calculated and listed in Table 3 and Table 4, and there is not much difference in energy consumption load for these two cases.

Our results are calculated under the assumption that each of the days used in this study is an average day, i.e. that the days preceding and following a given day are identical to the given day. We now turn our attention to a thought experiment for an alternate situation, that of several consecutive low solar radiation days followed by several consecutive high solar radiation days. The heavyweight structure will be able to store and release significant energy from one day to
Table 3. Energy consumption loads (on-off controller)

\begin{tabular}{cc}
\hline City, month, house \# & Energy consumption load (MJ/day) \\
\hline Busan, Aug., \#1 & 2.23 \\
Busan, Aug., \#2 & 1.19 \\
Busan, Jan., \#1 & 4.35 \\
Busan, Jan., \#2 & 4.13 \\
Seoul, Aug., \#1 & 3.80 \\
Seoul, Aug., \#2 & 2.75 \\
Seoul, Jan., \#1 & 8.43 \\
Seoul, Jan., \#2 & 7.21 \\
\hline
\end{tabular}

Table 4. Energy consumption loads (proportional controller, $\Gamma=$ $250 \mathrm{~W} /{ }^{\circ} \mathrm{C}$ )

\begin{tabular}{cc}
\hline City, month, house \# & Energy consumption load (MJ/day) \\
\hline Busan, Aug., \#1 & 2.30 \\
Busan, Aug., \#2 & 1.04 \\
Busan, Jan., \#1 & 4.72 \\
Busan, Jan., \#2 & 4.15 \\
Seoul, Aug., \#1 & 4.00 \\
Seoul, Aug., \#2 & 2.95 \\
Seoul, Jan., \#1 & 9.25 \\
Seoul, Jan., \#2 & 7.90 \\
\hline
\end{tabular}

the next. The fact that the simulations took eight (or so) days to converge lend credence to this. In such cases, the model would have to be exercised for the full period our approximate model is not valid in these cases.

In order to study interactions between the house compo- 


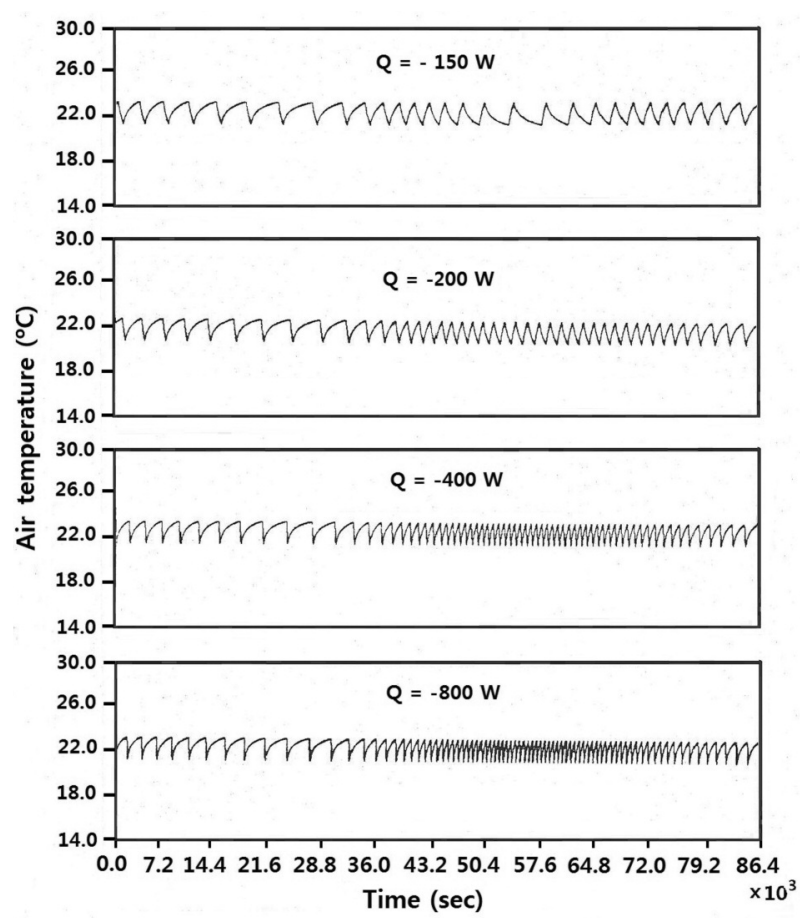

Fig. 5. Room air temperature variation for four different Q's (house \#1, Busan, Aug.)

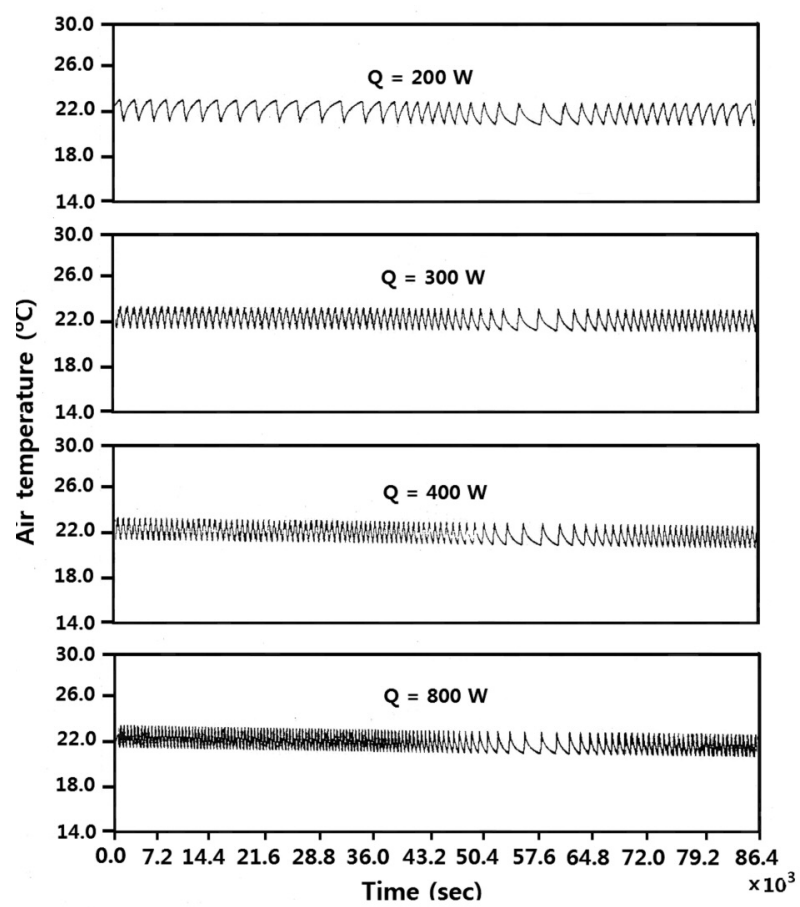

Fig. 6. Room air temperature variation for four different Q's (house \#1, Seoul, Jan.)

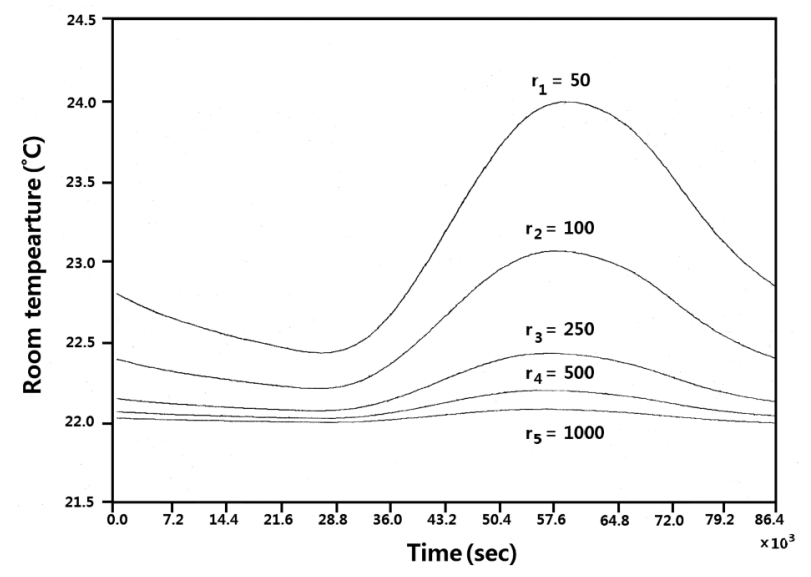

Fig. 7. Room air temperature variation for five different $\Gamma^{\prime}$ s (proportional controller, house \#1, Busan, Aug.)

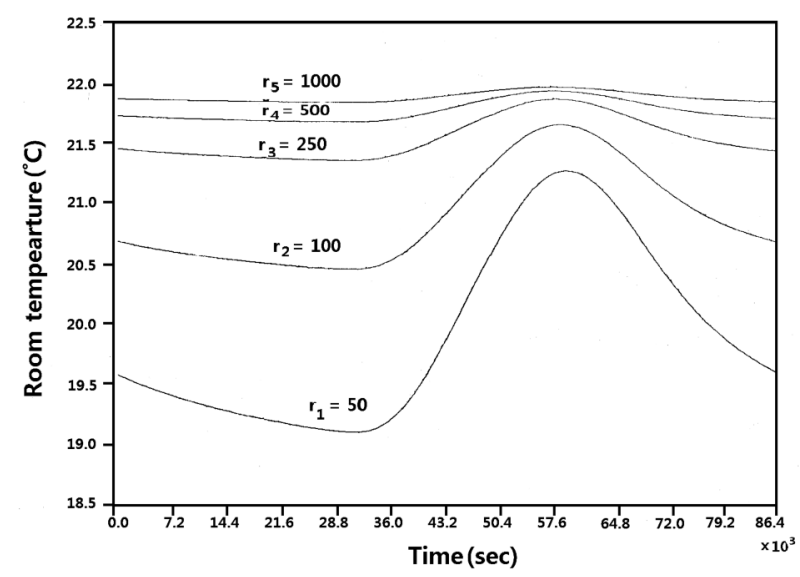

Fig. 8. Room air temperature variation for five different $\Gamma^{\prime}$ s (proportional controller, house \#1, Seoul, Jan.)

nents and the control, the room air temperature variations for four different Q's are plotted for different houses, cities, and months.

As shown in Fig. 5 and Fig. 6, the total number of cycles decreases as the absolute value of $Q$ decreases. The result indicates that there is not much difference in energy load for each case even though Q changes drastically. This is because energy inefficiencies due to cycling are not considered in this study. Choosing an optimum Q will be an important matter in practice as we seek a balance between comfort and energy usage.

As explained before, the output of the auxiliary energy source in this case is proportional to the difference between 
The study of the calculation of energy consumption load for heating and cooling in building using the Laplace Transform solution

Table 5. Comparison when different $\Gamma^{\prime}$ s are used for proportional control

\begin{tabular}{|c|c|c|c|c|c|c|c|c|c|}
\hline \multirow{2}{*}{$\begin{array}{c}\text { City, month, } \\
\text { house \# }\end{array}$} & \multirow{2}{*}{$\begin{array}{c}\Gamma \\
\left(\mathrm{W} /{ }^{\circ} \mathrm{C}\right)\end{array}$} & \multirow{2}{*}{$\begin{array}{l}\text { Load } \\
(\mathrm{MJ})\end{array}$} & $\overline{\mathrm{T}}_{\mathrm{A}}$ & $\overline{\mathrm{T}}_{0}$ & $\overline{\mathrm{T}}_{\mathrm{L}}$ & $\sigma_{\mathrm{TA}}$ & $\sigma_{\mathrm{T} 0}$ & $\sigma_{\mathrm{TL}}$ & $\sigma_{\mathrm{TS}}$ \\
\hline & & & \multicolumn{3}{|c|}{$\left({ }^{\circ} \mathrm{C}\right)$} & \multicolumn{4}{|c|}{$\left({ }^{\circ} \mathrm{C}\right)$} \\
\hline \multirow{5}{*}{$\begin{array}{c}\text { Busan } \\
\text { Aug. } \\
\# 1\end{array}$} & 50 & 2.15 & 23.12 & 31.71 & 23.58 & 0.56 & 6.50 & 0.80 & 1.25 \\
\hline & 100 & 2.25 & 22.58 & 31.70 & 23.07 & 0.30 & 6.50 & 0.55 & 0.67 \\
\hline & 250 & 2.30 & 22.25 & 31.69 & 22.75 & 0.12 & 6.50 & 0.40 & 0.27 \\
\hline & 500 & 2.33 & 22.12 & 31.69 & 22.61 & 0.06 & 6.50 & 0.34 & 0.13 \\
\hline & 1000 & 2.35 & 22.03 & 31.69 & 22.56 & 0.03 & 6.50 & 0.32 & 0.06 \\
\hline \multirow{5}{*}{$\begin{array}{c}\text { Seoul } \\
\text { Jan. } \\
\# 1\end{array}$} & 50 & 8.82 & 19.88 & 5.08 & 19.10 & 0.72 & 8.87 & 1.03 & 2.22 \\
\hline & 100 & 9.04 & 20.83 & 5.10 & 20.01 & 0.40 & 8.87 & 0.75 & 1.18 \\
\hline & 250 & 9.25 & 21.54 & 5.13 & 20.66 & 0.16 & 8.87 & 0.53 & 0.49 \\
\hline & 500 & 9.36 & 21.75 & 5.14 & 20.87 & 0.09 & 8.87 & 0.45 & 0.25 \\
\hline & 1000 & 9.41 & 21.87 & 5.14 & 20.98 & 0.05 & 8.87 & 0.40 & 0.13 \\
\hline
\end{tabular}

Table 6. Average temperatures (proportional controller)

\begin{tabular}{ccrc}
\hline City, month, house \# & $\overline{\mathrm{T}}_{\mathrm{A}}$ & $\overline{\mathrm{T}}_{0}$ & $\overline{\mathrm{T}}_{\mathrm{L}}$ \\
\hline Busan, Aug., \#1 & 21.97 & 21.70 & 21.95 \\
Busan, Aug., \#2 & 21.96 & 21.42 & 21.93 \\
Busan, Jan., \#1 & 21.82 & 10.20 & 21.54 \\
Busan, Jan., \#2 & 21.82 & 9.77 & 21.56 \\
Seoul, Aug., \#1 & 22.15 & 28.50 & 22.45 \\
Seoul, Aug., \#2 & 22.13 & 28.19 & 22.41 \\
Seoul, Jan., \#1 & 21.42 & 5.15 & 20.56 \\
Seoul, Jan., \#2 & 21.44 & 4.76 & 20.68 \\
\hline
\end{tabular}

the actual room air temperature and the set-point temperature. $\Gamma$ is referred to as the controller gain. Several values of $\Gamma$ are tested to obtain room air temperature trajectories, When too small a value of $\Gamma$ is used, the room air temperature lies between the comfort range and the sol-air temperature. This occurs because Q is not large enough to heat (or cool) the room air to approach $T_{s}$. Appropriate values of $\Gamma$ are determined after several trials for two houses.

Fig. 7 and Fig. 8 show the room air temperature variation for five different $\Gamma^{\prime}$ s. House \#1 is chosen for application. Busan in August and Seoul in January are used for weather conditions. A small $\Gamma$, such as $50 \mathrm{~W} /{ }^{\circ} \mathrm{C}$, results in temperatures far removed from the set-point temperature, while using a large $\Gamma$ makes the room air temperature very close to $T_{s}$.

A high temperature swing is observed in house \#1. This swing increases as $\Gamma$ decreases. Table 5 shows all these comparisons. The comfort level increases as $\Gamma$ increases, but this results in greater energy input. $\sigma$ in the Table is standard deviation.

Average values for $T_{A}, T_{0}$, and $T_{L}$ for proportional control such as $250 \mathrm{~W} /{ }^{\circ} \mathrm{C}$ of $\Gamma$ are also presented in Table 6. Again, a wall mass effect on the thermal behavior of a house exists in mild weather such as Busan but not so in extreme weather such as Seoul, which is the same conclusion reached in the case of on-off control.

\section{Conclusions}

An analytical solution based on a rigorous mathematical model has proved effective in comparing the energy consumption in two different types of houses and weather conditions. Useful information has been obtained in the categories of energy usage, comfort, and auxiliary system cycling rate.

There is a significant wall mass effect on the thermal performance of a building in mild weather conditions such as Busan. This effect is due to the thermal wave (due to ambient variability) penetrating the structure, and interacting in a nonlinear fashion with the auxiliary energy system controller. Buildings of heavyweight construction with insulation (house \#2) show the highest contort level in Busan. This is true both in terms of room air temperature, and mean radiant temperature as both fluctuate very little.

There is not much difference in energy load for each case even though Q changes drastically. This is because energy inefficiencies due to cycling are not considered in this study. A proportional controller provides the highest comfort levels in comparison with buildings using a on-off controller. Comfort can be increased by using a smaller dead band in the onoff controller. As far as energy consumption loads are concerned, there is no big difference between the proportional controller and the on-off controller. 
Finally, it appears that both mass and wall insulation are important factors in the thermal performance of houses in general, but their relative merits should be decided in each building by a strict analysis of the building layout, weather conditions, site location.

\section{Acknowledgment}

This work was supported by a Research Grant of Pukyong National University (C-D-2013-0428)

\section{References}

Brigham EO. 1974. The fast Fourier transform. Prentice Hall, Inc., New Jersey, USA, 25 - 150 .

Buffington DE. 1975. Heat gain by conduction through exterior walls and roofs-transmission matrix method. ASHRAE Transactions 81, Part 2, 89-101.

Carslaw HS and Jaeger JC, 1959. Conduction of heat in solids. Oxford Press, Great Britain, 92-326.

Christensen C and Perkins P. 1981. Effect of internal gain assumptions in building energy calculations. Solar Engineering, $408-$ 414.

Gadgil A, Bauman F and Kammerud, R. 1982. Natural convection in passive solar buildings: experiments, analysis and results. Passive Solar J 1 (1). 28 - 40.

Incropera PI, Dewitt DP, Bergman TL and Lavine AS. 2013. Foundations of heat transfer. John Wiley \& Sons, Inc., New York, USA, $111-194$.
Kreyszig E. 2011. Advanced engineering mathematics. John Wiley \& Sons, Inc., New York, USA, 540-600.

Kusuda T. 1976. Procedure employed by the ASHRAE task group for the determination of heating and cooling loads for building energy analysis. ASHRAE Transactions 82 (1), $305-314$.

Marks' standard handbook for mechanical engineers. 1978. McGraw-Hill, Inc. New York, USA, 4-1 4-82.

Mitalas GP and Stephenson DG. 1967. Room thermal response factors. ASHRAE Transactions 73 (1), III.2.1 - III.2.10.

Modest MF. 1993. Radition heat transfer. McGraw-Hill, Inc. New York, USA, $483-500$.

Oosthuizen PH and Naylor D. 1999. Introduction to convective heat transfer analysis. McGraw-Hill, Inc. New York, USA, 426477.

Peavy BA, Powell FJ and Burch, DM. 1973. Dynamic thermal performance of an experimental masonry building. U.S. National Bureau of Standards, Build Sci 45, 112-136.

Sodha MS, Kaur B, Kumar A and BansaL, NK. 1986. A Comparison of the admittance and Fourier methods for predicting heating/cooling loads. Solar Energy 36 (2), 125-127.

Stephenson DG and Mitalas GP, 1967. Cooling load calculations by thermal response factor method. ASHRAE Transactions 73 (1), III.1.1 - III.1.7.

Winn CB. 1982. Controls in solar energy systems," Advances in Solar Energy, American Solar Energy Soc, Inc., 209-240.

2014. 7. 11 Received

2014. 8. 12 Revised

2014. 8. 26 Accepted 